\title{
Expect With Me: development and evaluation design for an innovative model of group prenatal care to improve perinatal outcomes
}

Shayna D. Cunningham*, Jessica B. Lewis, Jordan L. Thomas, Stephanie A. Grilo and Jeannette R. Ickovics

\begin{abstract}
Background: Despite biomedical advances and intervention efforts, rates of preterm birth and other adverse outcomes in the United States have remained relatively intransigent. Evidence suggests that group prenatal care can reduce these risks, with implications for maternal and child health as well as substantial cost savings. However, widespread dissemination presents challenges, in part because training and health systems have not been designed to deliver care in a group setting. This manuscript describes the design and evaluation of Expect With Me, an innovative model of group prenatal care with a strong integrated information technology (IT) platform designed to be scalable nationally.
\end{abstract}

Methods/Design: Expect With Me follows clinical guidelines from the American Congress of Obstetricians and Gynecologists. Expect With Me incorporates the best evidence-based features of existing models of group care with a novel integrated IT platform designed to improve patient engagement and support, enhance health behaviors and decision making, connect providers and patients, and improve health service delivery. A multisite prospective longitudinal cohort study is being conducted to examine the impact of Expect With Me on perinatal and postpartum outcomes, and to identify and address barriers to national scalability. Process and outcome evaluation will include quantitative and qualitative data collection at patient, provider, and organizational levels. Mixed-method data collection includes patient surveys, medical record reviews, patient focus groups; provider surveys, session evaluations, provider focus groups and in-depth interviews; an online tracking system; and clinical site visits. A two-to-one matched cohort of women receiving individual care from each site will provide a comparison group ( $n=1,000$ Expect With Me patients; $n=2,000$ individual care patients) for outcome and cost analyses.

Discussion: By bundling prevention and care services into a high-touch, high-tech group prenatal care model, Expect With Me has the potential to result in fundamental changes to the health care system to meet the "triple aim:" better healthcare quality, improved outcomes, and lower costs. Findings from this study will be used to optimize the dissemination and effectiveness of this model.

Trial registration: ClinicalTrials.gov, NCT02169024. Retrospectively registered on June 18, 2014.

Keywords: Implementation study, Pregnancy, Group prenatal care, Preterm birth, Innovation

* Correspondence: shayna.cunningham@yale.edu

Yale School of Public Health, 135 College Street, Room 226, New Haven, CT 06510, USA 


\section{Background}

Birth outcomes are a nationwide health improvement priority [1]. Nearly four million women in the United States give birth each year, and $84 \%$ will give birth in their lifetimes [2, 3]. Despite substantial biomedical advances and intervention efforts, rates of preterm birth (9.6\%) and low birthweight (8.1\%) in the United States have remained relatively intransigent over the past three decades [4] and are considerably higher than rates in all other developed nations [5]. Extreme racial and ethnic disparities persist in the prevalence of preterm birth and low birthweight as well as consequent infant mortality. Compared to non-Hispanic White women, Black women are about 50\% more likely to deliver preterm and 90\% more likely to deliver a low birthweight infant [4]. Infant mortality due to preterm or low birthweight is 3.5 times higher for Black women and nearly two times higher for Puerto Rican women, compared to non-Hispanic White women [6].

The financial and human costs associated with preterm and low birthweight babies are profound. These adverse birth outcomes account for $36 \%$ of all US infant deaths [7], and are associated with greater infant and childhood morbidity as well as increased health care costs. Complications of preterm birth include neurodevelopmental disabilities, school and behavioral problems, visual and hearing impairment, cardiovascular and metabolic disorders, and higher risk of preterm in the next generation [8, 9]. Low birthweight is associated with subsequent risk of coronary heart disease, hypertension, and diabetes [10], and has been linked to all-cause mortality among women, and premature death among men [11]. In 2005, the annual economic burden associated with preterm birth in the US exceeded $\$ 26$ billion [12]. Based on health care inflation from 2005 to 2015 [13], we estimate that these costs now would exceed $\$ 38$ billion. Employers pay an average of twelve times more for newborn medical care for a preterm birth than for a healthy, full-term baby in the first year of life [14]. Families incur direct medical and non-medical (e.g., special education) costs, as well as indirect costs (e.g., lost productivity). Moreover, preterm birth and low birthweight result in substantial emotional distress for parents who must advocate and make healthcare decisions for fragile newborns [15].

Preventive interventions to address preterm and low birthweight include quality improvement efforts to eliminate early elective deliveries, smoking cessation, limiting multiple embryo transfer for in-vitro fertilizations, progesterone therapy to help sustain pregnancies among women with prior spontaneous preterm birth, and cervical cerclage for women with short cervical lengths [16]. However, the causes of preterm birth are not well understood, and as many as two-thirds of preterm births have unknown etiologies [17]. Group prenatal care, involving shared medical visits among pregnant women, has been suggested as one way through which substantial improvements in birth outcomes may be achieved [18-21].

In group prenatal care, a credentialed prenatal provider (e.g., obstetrician, midwife) provides pregnancy care to eight to twelve women simultaneously during up to ten 90-120 min group visits, and follows American Congress of Obstetrics and Gynecology (ACOG) guidelines. These group sessions integrate pregnancy health assessments with additional education, skills building and peer support.

A recent meta-analysis concluded that group prenatal care was associated with a decreased rate of low birth weight overall and a reduction in risk for preterm birth for African American women, compared to individual care [22]. Significant clinical, methodological, and statistical heterogeneity between available studies limited the authors' ability to assess other outcomes. However, the studies Carter and colleagues deemed to be the most rigorous (i.e., two NIH-funded randomized controlled trials from our research group) documented that, compared to standard individual care, group prenatal care results in lower rates of preterm and small for gestational age babies, less incident sexually transmitted infections, healthier maternal weight trajectories, and fewer depressive symptoms as well as increased patient satisfaction with care [18, 21, 23-25]. These improved outcomes may be due to reduced stress and increased knowledge, motivation, and health care engagement, resulting from the additional education and support that group prenatal care patients received [26]. More research is needed to replicate the effects of group prenatal care on perinatal and postpartum outcomes, and to identify potential mechanisms through which group prenatal care impacts health.

Estimated cost savings associated with group prenatal care (due to improved outcomes) varies by geography, ranging from $\$ 750$ to $\$ 890$ per birth [27]. Currently, such savings are realized by payors, such as Medicaid and private health insurers-not clinical health systems providing care. According to analyses conducted by Optum (UnitedHealth Group), if one-half of pregnant women enrolled in Medicaid received group prenatal care, net savings to Medicaid would be approximately $\$ 12$ billion over the next decade [28]. A recent study aimed at determining Medicaid costs savings associated with a group prenatal care program in South Carolina documented a $\$ 2.3$ million return on investment, with an average savings of $\$ 22,667$ in health care expenditures for every preterm birth prevented [29].

Despite the potential for improved outcomes, group prenatal care currently is available to an estimated 3\% of pregnant women in the United States [30]. Although evidence suggests that, if given a choice, approximately 
$50 \%$ of women would choose to participate in group care [31], widespread dissemination of group prenatal care presents challenges. First, any disruptive innovation is likely to face challenges and resistance from complex systems, such as the healthcare system, which seek homeostasis [32]. Second, the healthcare system was not designed to provide patient care in groups (i.e., infrastructure: group space, information technology systems for patient scheduling, provider scheduling, charting). Providers have not been trained to deliver care in groups (e.g., group facilitation skills, providing $20 \mathrm{~h}$ of patient education per pregnancy). Providers are conditioned to keep new patients for continuity of care, not refer them to the provider starting the next new prenatal group, where they will receive the remainder of care (e.g., loss of billable hours, turf issues).

Transitioning a health system from individual to group prenatal care is a challenging task that requires an organizational culture that supports innovation, one or more champions who will lead change efforts, and buyin from administrators, clinicians, and staff [33, 34]. Moreover, a financial paradox exists whereby the healthcare delivery system bears the burden of transformation to provide group care, yet it is often not the financial beneficiary of outcome improvements. Often, prenatal clinics pay start-up (e.g., training) and ongoing (e.g., materials, accreditation) costs to deliver group prenatal care. However, much of the cost savings come from averted (or shorter) neonatal intensive care unit stays or reduced emergency department visits; those savings are not channeled back to prenatal clinics, but rather are realized by other departments or payors.

To promote more widespread adoption and sustainability of group prenatal care, we developed an innovative model of group prenatal care with a novel information technology (IT) platform, called Expect With Me. Expect With $\mathrm{Me}$ group prenatal care was designed to be scalable nationally at lower cost to clinical practices and healthcare systems through the use of technology and the engagement of payors. Since February 2014, Expect With Me has been implemented with more than 1,000 women in five sites in Nashville TN, Detroit MI, and McAllen TX. This paper describes the design of the intervention and evaluation plan to assess its implementation and impact on health care quality, outcomes, and costs.

\section{Expect With Me group prenatal care}

Expect With Me group prenatal care was designed based on: (1) principles of group care [35]; (2) evidence from randomized controlled trials demonstrating improved birth outcomes for women receiving prenatal care in a group format [18, 21]; (3) clinical guidelines for prenatal care delivery [36]; and (4) research on patient and provider engagement through social media and technology [37-39]. Designed with national dissemination as a primary consideration, Expect With Me incorporates the best evidence-based aspects of existing models of group care [22, 40-42] with a novel IT platform to improve patient engagement and support, enhance health behaviors and decision making, connect providers and patients, and improve health service delivery.

Expect With $\mathrm{Me}$ provides care to groups of 8-12 women of the same gestational age. Women receiving Expect With $\mathrm{Me}$ begin prenatal care in the traditional manner. Formal intake (history, exam) is performed at an initial visit prior to group assignment. All prenatal care thereafter occurs within a group setting, except for health issues that require privacy and cervical assessments in late pregnancy. Ultrasounds and laboratory screenings occur per ACOG clinical guidelines [36]. Expect With $\mathrm{Me}$ is implemented from week 14 of pregnancy (after initial individual assessment) through delivery, following the same schedule as individual care. However, group visits are 90-120 min each, and follow a unique structured curriculum that incorporates the standard content of prenatal care, and emphasizes critical contemporary health issues relevant to pregnancy, such as nutrition, physical activity, stress/mental health, and sexual health. Table 1 summarizes the timing and recommended topics to be covered during each session. Participants may bring their partner, family member, or other support person to group sessions.

In a group setting, credentialed prenatal providers (e.g., obstetrician, midwife) conduct one-on-one assessments with each patient $(30 \mathrm{~min})$ and then facilitate group discussions on the topics of pregnancy, using adult learning principles (60-90 min). Facilitated discussions allow patients to provide and receive peer support while gaining knowledge and skills related to explicit learning objectives on pregnancy, childbirth, and parenting [43]. Expect With Me meets a broader set of needs for pregnant women (e.g., medical, social, educational) than traditional care; yet, it is fully reimbursable by health insurance programs as prenatal care. Further, women access the IT platform during their prenatal visit to track their own health metrics (e.g., weight, blood pressure, visit attendance). This encourages patient engagement in self-care and introduces them to the online experience of care that will continue throughout their pregnancy and postpartum.

Expect With $\mathrm{Me}$ has a novel, HIPPA-secure, integrated IT platform that enables patients to track their own health metrics, communicate with health providers and fellow group patients, access healthcare resources and educational materials, provide and gain support (Fig. 1). It is optimized for use on smartphones and computers, with all content available in English and Spanish via a single toggle. 
Table 1 Expect With Me group prenatal care session timing and topics

\begin{tabular}{|c|c|c|}
\hline Session & Themes & Topics \\
\hline 1 (13-17 weeks) & You're a healthy mom & $\begin{array}{l}\text { - Eat and live healthy for you and your baby } \\
\text { - Stay active while you're expecting } \\
\text { - Maintain healthy weight during pregnancy } \\
\text { - Understand routine prenatal testing and emergencies } \\
\text { - Know what blood pressure and weight numbers are healthy for you }\end{array}$ \\
\hline 2 (17-21 weeks) & Staying healthy and strong through change & $\begin{array}{l}\text { - How babies grow and develop } \\
\text { - Mom's clean teeth = healthier mother and baby } \\
\text { - Learn why you're feeling the way you do } \\
\text { - Move safely and comfortably while pregnant } \\
\text { - Get a good night's sleep } \\
\text { - Keep calm and stress-free while expecting } \\
\text { - Stay safe at home, work and play }\end{array}$ \\
\hline 3 (21-24 weeks) & Breastfeeding $=$ Healthy Babies and Healthy Moms & $\begin{array}{l}\text { - Benefits of breastfeeding } \\
\text { - Barriers to breastfeeding } \\
\text { - Basics of breastfeeding } \\
\text { - Choose a pediatric provider (Part 1) } \\
\text { - Your support systems (Part 1) }\end{array}$ \\
\hline 4 (25-29 weeks) & Healthy moms building healthy relationships & $\begin{array}{l}\text { - Understand Gestational Diabetes Testing } \\
\text { - Build healthy relationships } \\
\text { - Prevent STDs including HIV (Part 1) } \\
\text { - Choose when to get pregnant (Part 1) }\end{array}$ \\
\hline 5 (27-31 weeks) & Healthy moms and healthy labor & $\begin{array}{l}\text { - Signs of labor } \\
\text { - Stages of labor (Part 1) } \\
\text { - Fetal heart rate monitoring } \\
\text { - Stay comfortable during labor } \\
\text { - Understand Cesarean birth }\end{array}$ \\
\hline 6 (29-33 weeks) & Healthy labor & $\begin{array}{l}\text { - Stages of Labor (Part 2) } \\
\text { - What happens immediately after delivery } \\
\text { - Labor and delivery decisions } \\
\text { - Provider policies and options for labor and delivery } \\
\text { - Prevent STDs including HIV (Part 2) }\end{array}$ \\
\hline 7 (31-35 weeks) & Healthy labor and healthy relationships & $\begin{array}{l}\text { - Prepare for hospital stay and return home } \\
\text { - Negotiate to build healthy relationships } \\
\text { - Understand Group B Strep testing and prevention }\end{array}$ \\
\hline 8 (33-37 weeks) & Taking care of mom and baby & $\begin{array}{l}\text { - Caring for your baby } \\
\text { - Choose a pediatric provider (Part 2) } \\
\text { - Care for your postpartum body } \\
\text { - Set goals to build healthy relationships (Part 1) }\end{array}$ \\
\hline 9 (35-39 weeks) & Preparing for a Healthy Future & $\begin{array}{l}\text { - How to breastfeed } \\
\text { - Staying healthy and strong after pregnancy } \\
\text { - Signs of postpartum depression } \\
\text { - Make sure your home is safe you and your baby }\end{array}$ \\
\hline 10 (37+ weeks) & Build a healthy future & $\begin{array}{l}\text { - Choosing a daycare provider } \\
\text { - Going back to work } \\
\text { - Your support systems (Part 2) } \\
\text { - Choose when to get pregnant again (Part 2) } \\
\text { - Set goals for a healthy relationship (Part 2) }\end{array}$ \\
\hline
\end{tabular}

Personalized profiles allow patients to log vital signs (i.e., blood pressure, weight) during prenatal visits and to view their own weight trajectory across pregnancy. It also prompts them to track health behaviors (e.g., taking prenatal vitamin, drinking water, exercising) when they log in. Patients can access educational materials, including videos, tip sheets, audio files with relaxation/mindful meditation exercises, and links to online resources. Women can journal about their pregnancy experience, send messages to other women in their group, participate in discussion board conversations, and send out birth announcements.
Expect With Me's integrated information technology platform has numerous features to ease clinical implementation and aid practice management. All facilitator and patient handbooks are available electronically in both English and Spanish, eliminating the need for costly printing of materials. Prenatal care providers can use the IT platform to monitor attendance, upload and distribute educational materials to patients between visits, document care/content delivered, identify patient needs, and plan targeted care, such as inclusion of an HIV counselor or nutritionist in the next session. A 


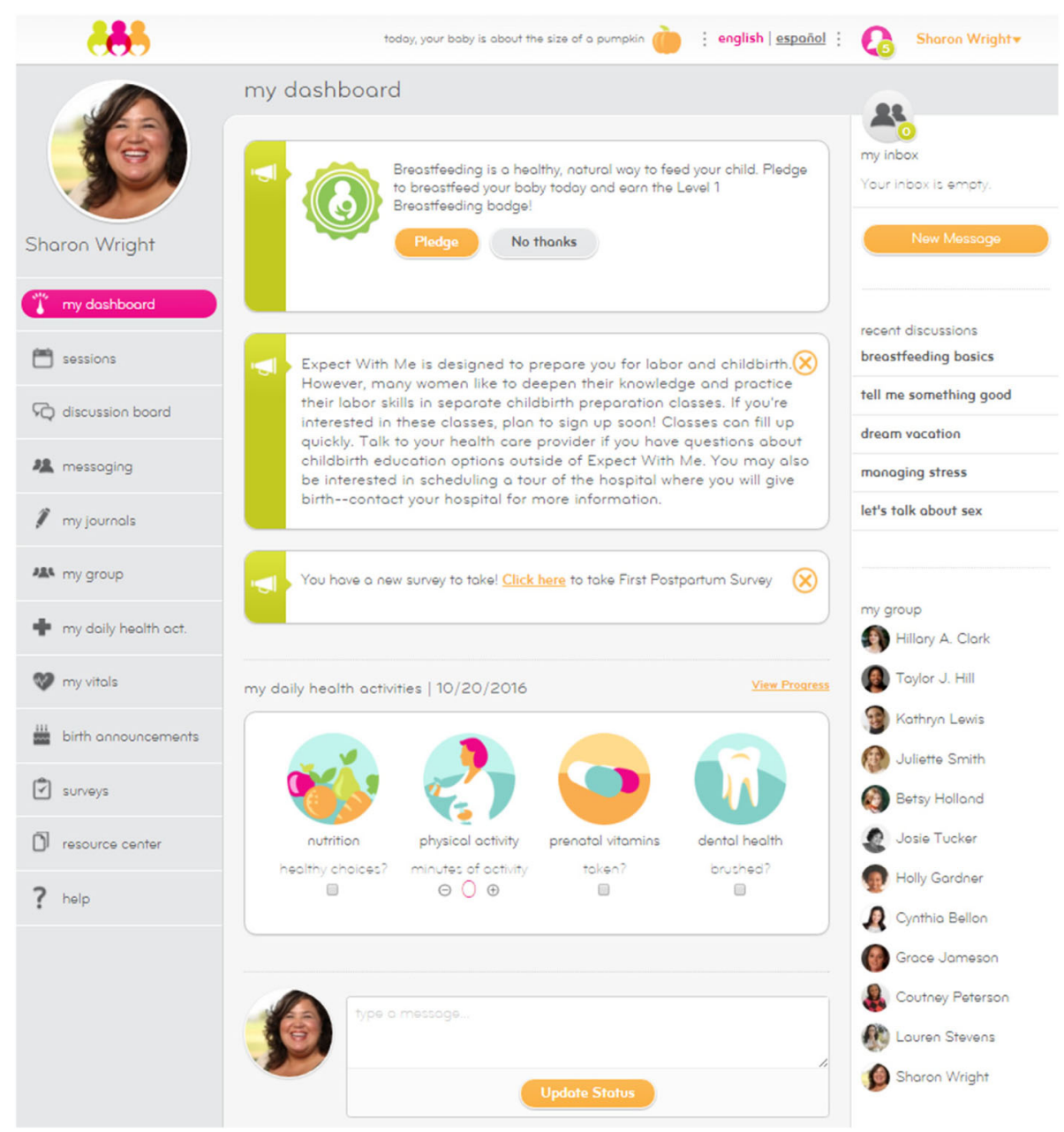

Fig. 1 Expect With Me IT platform: Select patient views (all patient names and photographs are fictional)

scheduling tool is available to aid the establishment group care schedules that account for provider time, group space, clinic schedules, holidays and more. Health systems have access to real-time data on patient demographics and adherence, to monitor and evaluate implementation success (Fig. 2).

\section{Development of Expect With Me: theoretical basis and formative research}

Expect With $M e$ was developed by a transdisciplinary team of researchers at Yale University, representatives from UnitedHealth Group, and health care providers at Vanderbilt University Medical Center. It is based on principles of group care, which assert that care is most effectively and efficiently provided in groups, that learning and support are enhanced, and that this high quality of care is difficult to achieve within the traditional structure of individual examination room visits [35, 44, 45]. Group prenatal care provides substantially more contact with providers (from two hours across pregnancy in individual care to $20 \mathrm{~h}$ in group), provides support services, and is integrated to respond to complex needs of pregnant women. Advantages of group interventions include, but are not limited to: improved learning and skills development, attitude change and motivation, enhanced insight through sharing of common experiences, and social support [43, 46]. In turn, groups facilitate development of new community norms for healthenhancing behaviors.

Expect With Me was designed using a human-centered design approach. Human-centered design is an iterative and participatory process to help ensure innovations are acceptable, usable, and meet the needs of users [47]. This approach has been used to shape healthcare to meet the multiple levels of need of clinicians and patient populations [48-51]. A series of key informant interviews with twenty prenatal care stakeholders and observational data collection during prenatal care visits were conducted, from which two important findings emerged. First, the healthcare industry historically has defined 


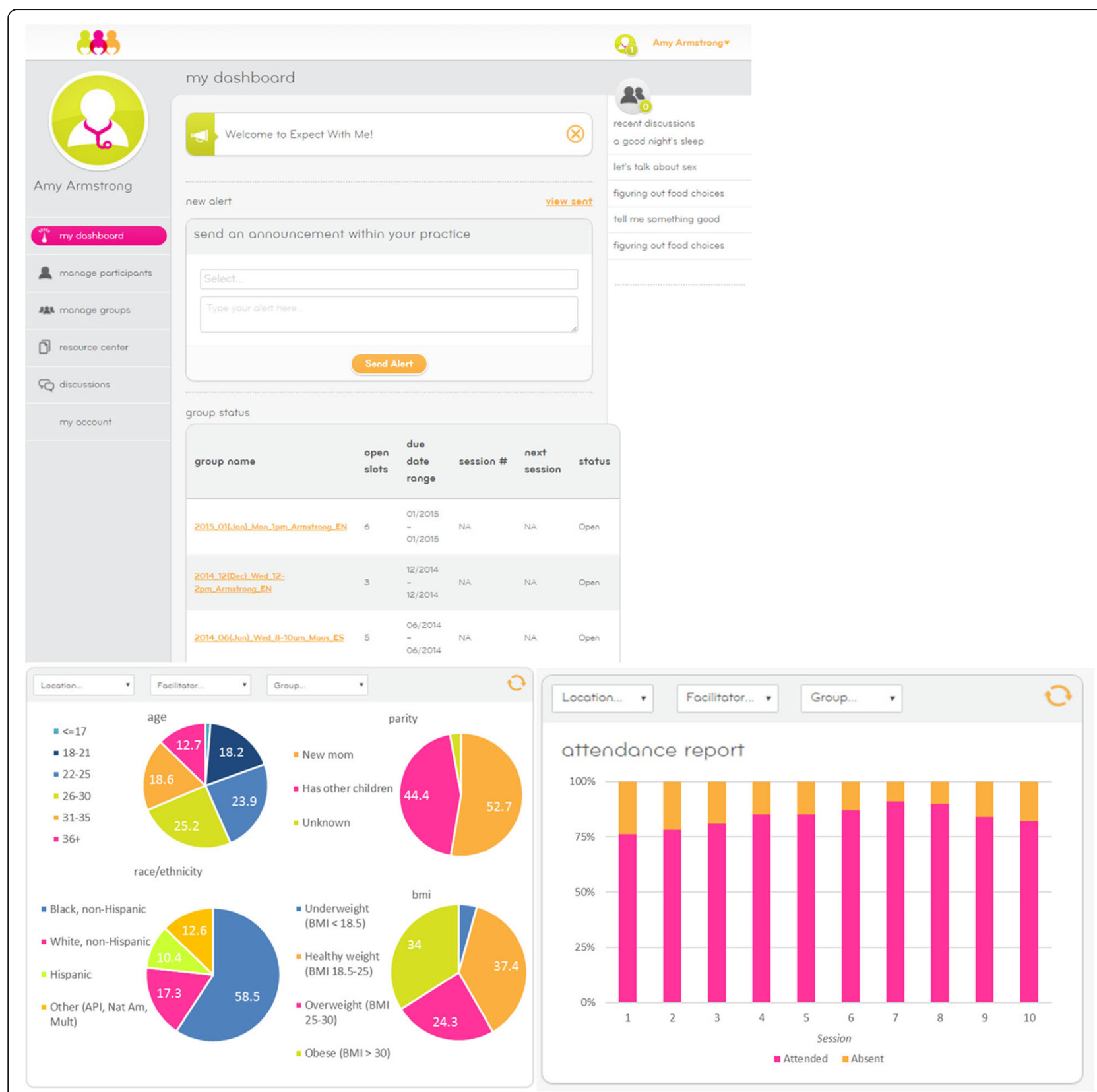

Fig. 2 Expect With Me IT platform: Select clinician views

prenatal care in medical terms, and an important value proposition of group prenatal care is that it provides a context in which other basic, safety, and social needs can be addressed. Second, pregnancy provides an opportunity to re-evaluate how those needs are being met, and prenatal care messaging would benefit by moving from a frame of fear and avoidance (e.g., what not to eat, drink, and do) to embracing good health habits for women and their families. An independent team of four curriculum development and writing professionals were commissioned and-following clinical guidelines from the American Congress of Obstetricians and Gynecologists and best practices for group facilitation-developed a ten-session structured curriculum and supplemental materials for the IT platform, grounded in the lessons learned during this process. To ensure accuracy, relevance, and feasibility, all content associated with Expect With $\mathrm{Me}$ (e.g., facilitator and patient handbooks, tip sheets and other resources) was reviewed by a medical team, including obstetricians/maternal-fetal medicine specialists, midwives, and pediatricians). A pilot study of Expect With $\mathrm{Me}$ was conducted with 243 pregnant women in Nashville TN; based on this pilot, revisions were made to enhance structure and content of the 
curriculum. The result of this extensive formative research is a supportive, comprehensive model of group prenatal care that aims to identify and address the full spectrum of pregnant women's needs throughout pregnancy and beyond, fostering long-term health for women and their families.

\section{Methods/Design}

Expect With $\mathrm{Me}$ is being evaluated via a multisite, longitudinal matched-cohort study, in which data are collected in a real-world settings at the patient and organizational levels. For national scale-up and sustainability, it is essential that the program not only be effective for patients but that the implementation strategy fits with the context of health clinics providing prenatal care [52]. A rigorous multi-method evaluation is being conducted to examine the impact of Expect With $\mathrm{Me}$ on maternal health and birth outcomes and identify and address barriers to national scalability. Cost analyses are also planned.

The study includes a rigorous process and outcome evaluation. Birth outcomes are the primary study outcomes (e.g., preterm birth, birthweight, neonatal intensive care unit admission/duration). Maternal psychosocial, health behaviors, and health outcomes (e.g., depression, breastfeeding, postpartum weight loss) are secondary outcomes.

The process evaluation will identify factors that influence uptake, fidelity, and sustainability of Expect With Me to inform scalability. We will employ quantitative approaches, such as online surveys and health record reviews as well as systematic qualitative approaches, such as in-depth interviews and focus groups. Key components of comprehensive process evaluations specified by Steckler and Linnan [53] will be adapted to meet the specific needs of this study. Uptake will include reach (number of groups offered); dose delivered (extent to which providers enroll patients and facilitate Expect With $\mathrm{Me}$ sessions); and dose received (willingness of eligible patients to participate; attendance in group sessions). Fidelity refers to the quality and integrity of the intervention as conceived, and is a function of implementation by clinical sites. We will examine how groups were planned and populated, the content and process of each session, and the perceptions of site staff and patients about Expect With Me. We will document whether Expect With Me patients received the intended exposure to the intervention, including attendance at each session; proportion of prenatal visits delivered in group; and patient use of IT platform. Sustainability will be driven, in part, by the impact of Expect With Me on healthcare costs. We will analyze the impact of birth outcomes on healthcare costs. We will document differences in utilization of care (e.g., emergency department, neonatal intensive care unit) between Expect With $\mathrm{Me}$ and individual care. Sustainability is impacted by depth of training and satisfaction with Expect With $\mathrm{Me}$ by providers and staff. We will document penetration of staff trainings and collect feedback from clinical site personnel. These data can be used to scale this intervention, nationally.

\section{Organizations and study population}

Beginning February 2014, Expect With Me was implemented in five clinical sites in Nashville TN, Detroit MI, and McAllen TX. Each site receives financial and advisory assistance to support the implementation and evaluation process. Yale and UnitedHealth Group recruited clinical sites. An important goal was to include sites located across different regions with different target populations. Interested sites completed a site eligibility form/site profile. If an organization met criteria to participate, a site visit was conducted by the research team to discuss the program procedures and requirements for participation in the study in more detail. The inclusion criteria for health care organizations was as follows: sufficient obstetric patient volume to meet study recruitment goals; support within the institution to integrate group prenatal care into practice; willingness to implement Expect With Me according to protocol during the study period; participation in the evaluation study data collection activities; and intention to continue Expect With Me after the project period.

To collect organizational data, all clinic staff involved in implementing Expect With Me were asked to participate in the process evaluation. To collect extensive data on individual-level outcomes, patients who participate in Expect With $\mathrm{Me}$ are required to enroll in the evaluation study. We aim to follow more than 1,000 pregnant women through one-year postpartum. Inclusion criteria for patients are as follows: less than 24 weeks pregnant; no severe medical problem requiring individual care only, as determined by the clinical practice; ability to speak English or Spanish; and willingness to participate in the study. Staff at each clinical site explain the study to eligible participants, answer questions, and obtain informed consent. A two-to-one matched cohort of women receiving standard individual care at each clinical site will provide the comparison for the outcome evaluation (two individual care patients for each group care patient). The matched cohort inclusion criteria mirror the study inclusion criteria (e.g., receiving prenatal care at the same clinical practice, entered prenatal care $<24$ weeks gestation, not transferred out to a high-risk clinic, fluent in English or Spanish, entered prenatal care during the study timeframe). All procedures have been approved by the Yale University Institutional Review Board and Institutional Review Boards at each study site. 


\section{Training and technical assistance}

Training for Expect With $\mathrm{Me}$ is a multi-phase process that targets health system staff at several levels. These phases include: (1) readiness planning and change management; (2) organizational training; (3) facilitator training; and (4) ongoing technical assistance. For several months prior to the start of patient enrollment in Expect With $M e$, health system leadership met regularly with the study team to prepare and build excitement for this care innovation. A series of webinars were conducted and emails sent to prenatal clinic staff providing general overview of Expect With $\mathrm{Me}$ and the benefits of group prenatal care for practices and patients. A one-day interactive organizational training was held to further familiarize prenatal clinic staff-from front desk staff to medical assistants to nurses, midwives, and obstetricians-with Expect With Me and each person's role in making group prenatal care a thriving part of their practice. This training prepared prenatal clinics to begin Expect With Me care, including group scheduling, talking to new obstetric patients about group prenatal care, and using the IT platform. Clinical staff who would lead Expect With Me groups (e.g., obstetricians, midwives, nurses, medical assistants) participated in a one- to twoday training focused on the development of group facilitation skills. Study staff monitor implementation at each site in real-time through the IT platform and offer technical assistance through regularly scheduled calls to provide ongoing support, share learnings across sites, and troubleshoot issues, as needed. Site visits are conducted to ensure fidelity and support implementation. In-person meetings with all participating sites allow administrators and clinical staff to share knowledge and experience with Expect With Me. Group discussions during these meetings provide insights into the implementation process within different clinical settings, and determinants of successful implementation.

\section{Data collection and measurement}

Both quantitative and qualitative data are being obtained at the organizational and patient levels. Table 2 shows how each of the data collection strategies will be used to assess key study outcomes.

\section{Organizational-level: online tracking system}

The Expect With Me IT platform was developed to collect real-time program implementation data, including the following information about every Expect With $\mathrm{Me}$ group: location, facilitators, session dates and times, group composition (e.g., number, gestational age range, and sociodemographic characteristics of participants), and session attendance rates.

\section{Organizational-level: provider surveys and session} evaluations

Group facilitators at each site are asked to complete a questionnaire at baseline and one-year later. Items assessed include provider: demographics, clinical training, previous experience with group care models (baseline only); attitudes about group prenatal care; and perceptions of barriers and facilitators to implementing and sustaining Expect With Me. Group facilitators also complete a session evaluation following each prenatal care session scheduled. Data captured by each session evaluation includes: whether or not the session occurred; if a session did not occur, why was it cancelled and the follow-up plan to ensure patients receive their prenatal care; if the session did occur, the topics covered during the group discussion, time spent on physical assessments, and an assessment of the group dynamics and factors that may have influenced attendance or delivery of the session as planned.

\section{Organizational-level: focus groups and in-depth interviews}

Many factors can potentially influence providers' implementation behaviors including characteristics of the innovation (e.g., complexity, compatibility and alignment with clinic policy, culture, current practices), social setting (e.g., societal norms about prenatal care), organizational context (e.g., support, resources), innovation strategies (e.g., training, reimbursement), patient (e.g., attitudes, adherence to recommended care), and the individual provider (e.g., skills, attitudes) [54, 55]. Focus groups and in-depth qualitative interviews will be conducted with 30 50 key informants (i.e., health care providers, support staff, administrators), until saturation is reached, to identify key factors associated with implementation behavior that can inform strategies to promote adoption, effective delivery, and sustainability of Expect With Me. In-depth interviews will last approximately $45 \mathrm{~min}$ and focus groups will last approximately $60 \mathrm{~min}$ and be audiotaped and transcribed.

\section{Organizational-level: site visits}

During site visits, study team members conduct selective observations of key interactions in prenatal care for patients (e.g., enrollment, group sessions) as well as relevant meetings and other onsite activities. Following each visit, site teams participate in debriefing sessions. Reflections and observations will be synthesized in written form and further examined as part of qualitative data analyses.

\section{Patient-level: surveys}

Expect With Me participants complete five surveys: baseline (second trimester), third trimester, birth, 6-months postpartum, and 12-months postpartum. Online survey 
Table 2 Assessment of key study outcomes

\begin{tabular}{|c|c|c|c|}
\hline Outcome & Definition & Measure & Data Collection Strategy \\
\hline \multicolumn{4}{|c|}{ Outcome evaluation } \\
\hline Effectiveness & $\begin{array}{l}\text { Impact of Expect With Me on patient } \\
\text { outcomes }\end{array}$ & $\begin{array}{l}\frac{\text { Patient-level }}{\text { - Comparison of birth outcomes between Expect }} \\
\text { With Me patients and the matched cohort who } \\
\text { received individual care }\end{array}$ & $\begin{array}{l}\text { - Health record reviews } \\
\text { - Patient surveys }\end{array}$ \\
\hline \multicolumn{4}{|c|}{ Process evaluation } \\
\hline \multirow[t]{2}{*}{ Uptake } & $\begin{array}{l}\text { Extent to which providers refer patients } \\
\text { to Expect With Me and deliver group } \\
\text { prenatal care sessions }\end{array}$ & $\begin{array}{l}\text { Organization-level } \\
\text { - Number and proportion of providers referring } \\
\text { patients for Expect With Me during the enrollment } \\
\text { period } \\
\text { - Number and proportion of providers delivering } \\
\text { Expect With Me group prenatal care sessions }\end{array}$ & - Health record reviews \\
\hline & $\begin{array}{l}\text { Willingness of eligible patients to } \\
\text { participate in Expect With Me and } \\
\text { extent to which they are } \\
\text { representative of the target } \\
\text { population }\end{array}$ & $\begin{array}{l}\frac{\text { Patient-level }}{\text { - Number and proportion of eligible patients }} \\
\text { enrolled in Expect With Me } \\
\text { - Characteristics of Expect With Me participants } \\
\text { - Reasons patients participate/do not participate }\end{array}$ & $\begin{array}{l}\text { - Health record reviews } \\
\text { - Online tracking system } \\
\text { - Patient surveys and focus groups }\end{array}$ \\
\hline \multirow[t]{2}{*}{ Fidelity } & $\begin{array}{l}\text { Extent to which Expect With Me is } \\
\text { implemented as planned }\end{array}$ & \multirow{2}{*}{$\begin{array}{l}\text { Organization-level } \\
\text { - Conformity to the implementation strategy } \\
\text { - Conformity to the implementation content } \\
\text { - Amount of sessions/groups completed } \\
\text { - Amount of content delivered per session } \\
\text { - Clinic staff perception about Expect With } \\
\text { Me's content and implementation strategy } \\
\text { - Satisfaction about implementation within } \\
\text { the clinic } \\
\frac{\text { Patient-level }}{- \text { Amount of sessions attended }} \\
\text { - Amount of information technology platform use }\end{array}$} & \multirow{2}{*}{$\begin{array}{l}\text { - Online tracking system } \\
\text { - Session evaluations } \\
\text { - Provider interviews and focus } \\
\text { groups } \\
\text { - Patient surveys and focus groups } \\
\text { - Site visits }\end{array}$} \\
\hline & $\begin{array}{l}\text { Amount of the program received by } \\
\text { patients }\end{array}$ & & \\
\hline \multirow[t]{2}{*}{ Sustainability } & $\begin{array}{l}\text { Impact of Expect With Me on healthcare } \\
\text { costs }\end{array}$ & \multirow{2}{*}{$\begin{array}{l}\text { Organization-level } \\
\text { - Comparison of financial impact of birth outcomes } \\
\text { on healthcare costs } \\
\text { - Comparison of utilization of healthcare, including } \\
\text { visit attendance, emergency department and } \\
\text { neonatal intensive care unit utilization, postpartum } \\
\text { long acting reversible contraception uptake, and } \\
\text { associated costs } \\
\text { - Satisfaction with Expect With Me group care and } \\
\text { provider training on group care }\end{array}$} & \multirow{2}{*}{$\begin{array}{l}\text { - Health record reviews } \\
\text { - Billing records } \\
\text { - Provider focus groups } \\
\text { - Provider surveys }\end{array}$} \\
\hline & $\begin{array}{l}\text { Opinion about Expect With Me and the } \\
\text { implementation strategy }\end{array}$ & & \\
\hline
\end{tabular}

technology provides standardized measurement, computercontrolled branching through complex questionnaires, automated consistency and range checking, and multilingual administration of questions. Studies with high-risk populations have concluded that computer administered surveys provide valid and more accurate reporting of high-risk behaviors [56-59].

The baseline survey is the most comprehensive and includes patient sociodemographic characteristics and medical history. Follow-up interviews are shorter and assess changes in health-related attitudes and behaviors, as well as prenatal care satisfaction, infant nutrition, and maternal and child health care utilization. Measures include items related to: general health behaviors (e.g., smoking and drinking, diet, physical activity), pregnancy-related attitudes and health (e.g., readiness for labor and care, weight gain and retention), sexual health and risk (e.g., sexual activity, condom use and self-efficacy, intimate partner violence), depression, stress, discrimination, social support, resilience, internet access and use, infant feeding practices (e.g., breastfeeding intention and behavior, introduction of solid foods), and health care system utilization (e.g., emergency room visits, pediatric visits). All of the survey measures were selected from previous research; most have been validated with similar clinical populations $[18,21]$.

\section{Patient-level: medical record review}

Primary outcomes and other maternal and infant healthrelated data will be gathered via prenatal, labor and delivery, and postpartum medical record extraction. Record extraction for each patient will be completed after 12 -weeks post childbirth and one-year postpartum. Data collected will include medical and reproductive health history, prenatal visit attendance and vital signs (e.g., weight and blood pressure), pregnancy complications and outcomes, delivery information, birth outcomes (e.g., 
gestational age, birth weight), any neonatal intensive care admission/length of stay, and postpartum healthcare.

\section{Patient-level: focus groups}

Focus groups will be conducted at each site with patients who have delivered their babies. Approximately 40 women will participate. The focus groups will be facilitated by two study team members, last $60-90 \mathrm{~min}$, and be audiotaped and transcribed. Topics covered will include perceptions of prenatal visits, services and support received from the health system, curriculum, IT platform, and impact of the program on family health and well-being.

\section{Analyses}

Descriptive analyses of quantitative data will be performed. Women who participated in group prenatal care and those who received individual care will be matched on the basis of propensity scores. Propensity score matching is a statistical technique to correct for observable difference between the treated and non-treated group, thereby reducing selection bias and strengthening causal inferences, in observational studies [60]. We will use multiple imputation and maximum likelihood techniques to handle missing data and sensitivity analyses to assess the robustness of inferences about treatment effects to various missing data assumptions, as needed.

Generalized linear and logistic regression models will be used to analyze continuous (e.g., gestational age at delivery and birth weight) and dichotomous outcomes (e.g., preterm birth, low birth weight), respectively. Negative binomial regression models will be used to analyze count outcomes (e.g., neonatal intensive care unit days). Each model will include a main effect for treatment group (Expect With Me vs. individual care). Because many women who attend group prenatal care sessions also supplement with individual visits [61], adjusted models will control for number of individual visits, as well as contain predictor variables that are clinically meaningful to a specific hypothesis of interest.

Trajectories of change for outcomes that are repeatedly measured over time (e.g., weight) will be examined using linear and non-linear mixed effects modeling, with a random effect for subject. An optimal covariance structure will be selected based on the likelihood ratio test for nested models and based on the Akaike Information Criterion for non-nested models [62]. The main independent effects of time, treatment, and second-degree interactions of these predictors will be considered in each model, adjusting for other covariates as described above.

Multilevel mixed models will be used to identify factors that influence primary outcomes among Expect With Me patients, with the effect of site modeled as a random effect. A scale variable that will reflect a woman's attendance level at prenatal care group visits will be created to evaluate whether there is a "dose-response" intervention effect. Structural equation models will be used to examine factors that may mediate the relationship between participation in group care sessions and improved outcomes.

Focus group and in-depth interview data will be entered into NVivo 10 (QSR International Pty Ltd, Australia) and analyzed using the constant comparative method [63]. This type of thematic analysis is useful for identifying, examining, and reporting patterns within the data [64]. Coding of textual data will occur in iterative steps, in which codes are defined and then refined during review of transcripts from successive interviews and focus groups. Study team members will independently code transcripts. Intercoder reliability will be assessed, joint sessions held to discuss discrepancies, and final codes assigned to observations by a negotiated, group process. We will employ best practices for qualitative research including searching for disconfirming evidence, interviewing multiple respondents at each site for triangulation, and maintaining a detailed audit trail to document analytic decisions [63]. The qualitative data will also be used to interpret and extend the quantitative data findings.

\section{Cost analyses}

The evaluation will include cost analyses $[65,66]$ comparing Expect With $\mathrm{Me}$ to individual care, based on patient outcomes (e.g., neonatal intensive care unit admissions and length of stay, emergency department visits). Data from each clinical site's billing and accounting systems will be used determine patients' health care charges and actual costs (i.e., amount paid for care collected by the health care facility) including minimum, maximum, median, and interquartile range values of costs for the entire pregnancy through three months postpartum, as well as for the prenatal, childbirth, and postpartum periods separately.

Ordinary least squares (OLS) regressions will be used to test the association between type of care received and maternal and newborn health care costs. Regressions will control for maternal age, race, and other risk factors for adverse birth outcomes. Generalized linear models (GLM) estimates with a gamma distribution and logarithmic link will be used to confirm OLS findings. Alternative approaches to OLS models often are used to account for the long right tail of health care cost distributions. However, OLS results are easier to interpret than many alternative model results. Previous studies of Medicare spending and other health care costs indicated that OLS models perform as well and sometimes better than alternative expenditure models $[67,68]$.

Costs associated with the provision of group prenatal care from a practice perspective, including start-up and maintenance costs, will also be assessed to inform scalability. Estimates for replication costs will take into account different clinical practice and implementation characteristics. 


\section{Sample size}

Results from previous randomized controlled trials suggest that group prenatal reduces likelihood of delivering a preterm or small for gestational age baby by $33-34 \%$ [18, 21]. Based on these findings and the national preterm birth rate of $9.6 \%$ [4], we need a minimum of 1,768 study participants with one-third $(n=884)$ receiving group prenatal care to have power of .80 to detect differences at alpha $=0.05$ with a one-tailed test. With a potential $10 \%$ drop out rate due to miscarriage, pregnancy complications and changes in life circumstances (e.g., geographic move), we will recruit 1,000 women, expecting to follow more than 900 of them through one-year postpartum. We will compare primary maternal health and birth outcomes for these women with a 2-1 matched cohort of 2,000 patients receiving individual care. Therefore, the total study sample of women receiving both group and individual prenatal care will include a total of 3,000 women.

\section{Trial status}

This study has been registered on ClinicalTrials.gov as NCT02169024. All data collection will be completed by December 2017.

\section{Discussion}

Combined maternal and newborn care is the most common and expensive category of hospital care for all payers costing $\$ 52$ billion for Medicaid and \$40 billion for private insurers, annually [69]. High rates of preterm birth and low birth weight are important drivers of these costs. Moreover, gross disparities in these and other reproductive health outcomes are grounds for "evidence-based outrage" [70]. National initiatives to tackle disparities and rising rates of maternal morbidity and mortality [71-73] make a renewed focus on prenatal care access, structure, content and quality not only timely, but essential [74].

Group prenatal care has shown promise to reduce rates of adverse birth outcomes, particularly among African American women, but widespread dissemination of this important health care innovation has yet to realized. This paper describes the development and methods that are being used to comprehensively evaluate Expect With $M e$, an innovative model of group prenatal care with an integrated information technology platform designed to be scalable nationally.

Researchers, clinicians, health care administrators, insurers, and policy-makers will have significant interest in the results of this study if we can demonstrate that bundling prevention and care services into a high-touch, high-tech group prenatal care model (i.e., Expect With $\mathrm{Me}$ ) meets the "triple aim" for maternity care: better healthcare quality, improved outcomes, and lower health care costs. Most importantly, families will avoid the emotional toll and lifetime health and education costs associated with adverse birth outcomes. Findings from this study will be used to formulate recommendations to optimize the dissemination and effectiveness of this model of group prenatal care.

\section{Acknowledgments \\ We thank patients and providers at Vanderbilt University Medical Center, Wayne State University, and Doctors Hospital at Renaissance for their participation in the study. \\ Funding \\ This study is supported by a grant from United Health Foundation, with additional in-kind support from UnitedHealth Group. Neither United Health Foundation nor UnitedHealth Group had a role in the study design, data collection, and analysis, interpretation of results, or manuscript preparation.}

\section{Availability of data and materials}

Data sets will be made available for research purposes upon reasonable request after the end of the study.

\section{Authors' contributions}

All authors collaborated on the study design. $J$ and $J$ obtained funding. SC wrote the first draft of the manuscript with substantial contribution from $\mathrm{J}$, JT, SG, and JI. All authors contributed to critical revisions of the paper and read and approved the final manuscript.

\section{Competing interests}

The authors declare that they have no competing interests.

\section{Consent for publication}

Not applicable.

\section{Ethics approval and consent to participate}

Ethics approval including consent to participate procedures were approved by Institutional Review Boards at Yale University, Vanderbilt University, Wayne State University and the New England Institutional Review Board.

\section{Publisher's Note}

Springer Nature remains neutral with regard to jurisdictional claims in published maps and institutional affiliations.

Received: 23 January 2017 Accepted: 10 May 2017

Published online: 18 May 2017

\section{References}

1. Office of Disease Prevention and Health Promotion. Maternal, infant and child health. Washington, DC: Department of Health and Human Services; 2014.

2. Centers for Disease Control and Prevention. Births and natality 2014. 2016. http://www.cdc.gov/nchs/fastats/births.htm. Accessed 22 Dec 2016.

3. United States Census Bureau. Completed fertility for women 40 to 50 years old by selected characteristics: June 2014. 2014.

4. Hamilton B, Martin J, Osterman M. Births: preliminary data from 2015. Natl Vital Stat Rep. 2016;65:1-14.

5. Beck S, Wojdyla D, Say L, Betran AP, Merialdi M, Requejo JH, et al. The worldwide incidence of preterm birth: a systematic review of maternal mortality and morbidity. Bull World Health Organ. 2010;88:31-8.

6. Mathews T, MacDorman M, Thoma M. Infant mortality statistics from the 2013 period linked birth/infant death data set. Natl Vital Stat Rep. 2015;64:1-29.

7. Centers for Disease Control and Prevention. Preterm births. 2016. http:// www.cdc.gov/reproductivehealth/MaternallnfantHealth/PretermBirth.htm. Accessed 22 Dec 2016.

8. Saigal S, Doyle L. An overview of mortality and sequelae of preterm birth from infancy to adulthood. Lancet. 2008;371:261-9.

9. Blencowe H, Cousens S, Chou D, Oestergaard M, Say L, Moller AB, et al. Born too soon: the global epidemiology of 15 million preterm births. Reprod Health. 2013;10 Suppl 1:S2.

10. Barker D, Eriksson J, Forsen T, Osmond C. Fetal origins of adult disease: Strength of effects and biological basis. Int J Epidemiol. 2002;31:1235-9. 
11. Kajantie E, Osmond C, Barker D, Forsen T, Phillips D, Eriksson J. Size at birth as a predictor of mortality in adulthood: A follow-up of 350,000 person years. Int J Epidemiol. 2005;34:655-63.

12. Behrman R, Butler A. Preterm birth: causes, consequences, and prevention. Washington, DC: Institute of Medicine; 2007.

13. Patton M. US Health Care Costs Rise Faster Than Inflation. Forbes; 2015.

14. Truven Health Analytics Inc. Costs of Preterm Birth. Prepared for March of Dimes; 2013.

15. Hodek JM, von der Schulenburg JM, Mittendorf T. Measuring economic consequences of preterm birth - Methodological recommendations for the evaluation of personal burden on children and their caregivers. Health Econ Rev. 2011;1:6.

16. Chang HH, Larson J, Blencowe H, Spong CY, Howson CP, Cairns-Smith S, et al. Preventing preterm births: analysis of trends and potential reductions with interventions in 39 countries with very high human development index. Lancet. 2013;381:223-34.

17. Ferrero DM, Larson J, Jacobsson B, Di Renzo GC, Norman JE, Martin Jr JN, et al. Cross-country individual participant analysis of 4.1 million singleton births in 5 countries with very high human development index confirms known associations but provides no biologic explanation for $2 / 3$ of all preterm births. PLoS One. 2016;11:e0162506.

18. Ickovics JR, Kershaw TS, Westdahl C, Magriples U, Massey Z, Reynolds H, et al. Group prenatal care and perinatal outcomes: a randomized controlled trial. Obstet Gynecol. 2007;110(2 Pt 1):330-9.

19. Picklesimer AH, Billings D, Hale N, Blackhurst D, Covington-Kolb S. The effect of centering pregnancy group prenatal care on preterm birth in a lowincome population. Am J Obstet Gynecol. 2012;206:415.e411-7.

20. Edward McCabe. Prematurity Prevention Conference 2015: Quality Improvement, Evidence and Practice. Arlington: March of Dimes; 2015

21. Ickovics J, Earnshaw V, Lewis J, Kershaw T, Magriples U, Stasko E, et al. Cluster randomized controlled trial of group prenatal care: perinatal outcomes among adolescents in New York City health centers. Am J Public Health. 2016;106:359-65.

22. Carter EB, Temming LA, Akin J, Fowler S, Macones GA, Colditz GA, et al. Group prenatal care compared with traditional prenatal care: a systematic review and meta-analysis. Obstet Gynecol. 2016;128:551-61.

23. Kershaw TS, Magriples U, Westdahl C, Rising SS, Ickovics J. Pregnancy as a window of opportunity for HIV prevention: Effects of an HIV intervention delivered within prenatal care. Am J Public Health. 2009;99:2079-86.

24. Magriples U, Boynton MH, Kershaw T, Lewis J, Rising SS, Tobin JN, et al. The impact of group prenatal care on pregnancy and postpartum weight trajectories. Am J Obstet Gynecol. 2015;213:688.e681-9.

25. Felder J, Epel E, Lewis JB, Cunningham S, Tobin JN, Rising SS, et al. Effect of group prenatal care on depressive symptoms and associations with preterm birth: A cluster randomized control trial. J Consult Clin Psychol. (revise and resubmit December 2016).

26. Heberlein E, Picklesimer AH, Billings DL, Covington-Kolb S, Farber N, Frongillo EA. Qualitative comparison of women's perspectives on the functions and benefits of group and individual prenatal care. J Midwifery Womens Health. 2016;61:224-34.

27. Picklesimer AH. The SC Centering Story, Northeastern Centering Symposium. Waltham: Centering Healthcare Institute and March of Dimes; 2015.

28. UnitedHealth Center for Health Reform \& Modernization. 100 Percent of Our Future: Improving the Health of America's Children. Minneapolis: UnitedHealth Group; 2013.

29. Gareau S, Lòpez-De Fede A, Loudermilk BL, Cummings TH, Hardin JW, Picklesimer $\mathrm{AH}$, et al. Group prenatal care results in medicaid savings with better outcomes: A propensity score analysis of Centering Pregnancy participation in South Carolina. Matern Child Health J. 2016;20:1384-93.

30. Declercq ER, Sakala C, Corry MP, Applebaum S, Herrlich A. Listening to mothers III: pregnancy and birth. New York: Childbirth Connection; 2013.

31. McDonald SD, Sword W, Eryuzlu LN, Neupane B, Beyene J, Biringer AB. Why are half of women interested in participating in group prenatal care? Matern Child Health J. 2016;20:97-105.

32. Paina $L$, Peters $\mathrm{DH}$. Understanding pathways for scaling up health services through the lens of complex adaptive systems. Health Policy Plan. 2011;27: 365-73.

33. Novick G, Sadler LS, Knafl KA, Groce NE, Kennedy HP. In a hard spot: providing group prenatal care in two urban clinics. Midwifery. 2013;29:690-7.
34. Novick G, Womack JA, Lewis JB, Stasko EC, Rising SS, Sadler LS, et al. Perceptions of barriers and facilitators during implementation of a complex model of group prenatal care in six urban sites. Res Nurs Health. 2015;38: 462-74.

35. Noffsinger EB. Running group visits in your practice. London, New York: Springer Science \& Business Media; 2009.

36. American Academy of Pediatrics, American College of Obstetricians and Gynecologists. Guidelines for perinatal care. Elk Grove Village (IL) and Washington, DC: AAP and ACOG; 2012

37. Antheunis ML, Tates K, Nieboer TE. Patients' and health professionals' use of social media in health care: motives, barriers and expectations. Patient Educ Couns. 2013;92:426-31.

38. Greaves F, Ramirez-Cano D, Millett C, Darzi A, Donaldson L. Harnessing the cloud of patient experience: Using social media to detect poor quality healthcare. BMJ Qual Saf. 2013:22:183-6.

39. Cheston CC, Flickinger TE, Chisolm MS. Social media use in medical education: a systematic review. Acad Med. 2013;88:893-901.

40. Deakin T, McShane CE, Cade JE, Williams RD. Group based training for selfmanagement strategies in people with type 2 diabetes mellitus. Cochrane Database Syst Rev. 2005;2:CD003417.

41. Housden L, Wong ST, Dawes M. Effectiveness of group medical visits for improving diabetes care: a systematic review and meta-analysis. CMAJ. 2013;185:E635-44.

42. Catling CJ, Medley N, Foureur M, Ryan C, Leap N, Teate A, et al. Group versus conventional antenatal care for women. Cochrane Database Syst Rev. 2015:2:CD007622

43. Ashman A, Gillies R. Cooperative learning: The social and intellectual outcomes of learning in groups. Abingdon: Routledge; 2003.

44. Feldman M. Cluster visits. Am J Nurs. 1974;74:1485-8.

45. Massey Z, Rising SS, Ickovics JR. CenteringPregnancy group prenatal care: promoting relationship-centered care. J Obstet Gynecol Neonatal Nurs. 2006:35:286-94.

46. Hyde J, Appleby PR, Weiss G, Bailey J, Morgan X. Group-level interventions for persons living with HIV: A catalyst for individual change. AIDS Educ Prev. 2005;17(1 Suppl A):53-65.

47. International Organization for Standardization. Ergonomics of humansystem interaction - Part 210: Human-centred design for interactive systems. Available at: http://www.iso.org/iso/catalogue_detail. htm?csnumber=52075. Accessed 10 Mar 2016

48. Hartzler A, Izard J, Dalkin B, Mikles S, Gore J. Design and feasibility of integrating personalized PRO dashboards into prostate cancer care. J Am Med Inform Assoc. 2016;23:38-47.

49. Hartzler A, Chaudhuri S, Fey B, Flum D, Lavallee D. Integrating patientreported outcomes into spine surgical care through visual dashboards: Lessons learned from human-centered design. EGEMS. 2015;3:1133.

50. Salmon M, Salmon C, Bissinger A, Muller MM, Gebreyesus A, Geremew H, et al. Alternative ultrasound gel for a sustainable ultrasound program: application of human centered design. PLoS One. 2015;10:e0134332.

51. Brennan P, Downs S, Casper G. Project HealthDesign: Rethinking the power and potential of personal health records. J Biomed Inform. 2010;43:S3-5.

52. Wandersman A, Duffy J, Flaspohler P, Noonan R, Lubell K, Stillman L, et al. Bridging the gap between prevention research and practice: The interactive systems framework for dissemination and implementation. Am J Community Psychol. 2008:41:171-81.

53. Steckler A, Linnan L. Process evaluation for public health interventions and research. San Francisco: Jossey-Bass; 2002.

54. Chaudoir S, Dugan A, Barr C. Measuring factors affecting implementation of health innovations: a systematic review of structural, organizational, provider, patient, and innovation level measures. Implement Sci. 2013:8:22.

55. Huijg J, Crone M, Verheijden M, van der Zouwe N, Middelkoop B, Gebhardt $W$. Factors influencing the adoption, implementation, and continuation of physical activity interventions in primary health care: a Delphi study. BMC Fam Pract. 2013;14:142.

56. Sudman S, Bradburn N. Response effects in surveys. Chicago: Aldine; 1974.

57. Babor T, Brown J, del Boca F. Validity of self-reports in applied research on addictive behaviors: fact or fiction? Addict Behav. 1990;12:5-31.

58. Latkin C, Vlahov D, Anthony J. Socially desirable responding and selfreported HIV infection risk behaviors among intravenous drug users. Addiction. 1993;88:517-26

59. Meichenbaum D. Cognitive-behavior modification. Boston: Springer Science \& Business Media; 2013. 
60. Austin PC. A critical appraisal of propensity-score matching in the medical literature between 1996 and 2003. Stat Med. 2008;27:2037-49.

61. Cunningham SD, Grilo S, Lewis JB, Novick G, Rising SS, Tobin JN, et al. Group prenatal care attendance: Determinants and relationship with care satisfaction. Matern Child Health J. 2016 Aug;2. ePub ahead of print.

62. Burnham KP, Anderson DR. Model selection and multimodel inference: a practical information-theoretic approach. New York: Springer; 2002.

63. Patton MQ. Qualitative research and evaluation methods. Thousand Oaks: SAGE Publications; 2002.

64. Braun V, Clarke V. Using thematic analysis in psychology. Qual Res Psychol. 2008:3:77-101.

65. Drummond M, Sculpher M, Torrance G, O'Brien B, Stoddart G. Methods for the economic evaluation of health care programmes. Oxford: University Press; 2005.

66. Boardman A, Greenberg D, Vining A, Weimer D. Cost-Benefit Analysis: Concepts and Practice. Pearson Series in Economics; 2014.

67. Basu A, Manning WG. Issues for the next generation of health care cost analyses. Med Care. 2009;47(7 Suppl 1):S109-14.

68. Buntin MB, Zaslavsky AM. Too much ado about two-part models and transformation? comparing methods of modeling medicare expenditures. J Health Econ. 2004;23:525-42.

69. Wier LM, Andrews RM. The national hospital bill: the most expensive conditions by payer, 2008. Rockville: Agency for Healthcare Research and Quality; 2011.

70. Eichelberger KY, Doll K, Ekpo GE, Zerden ML. Black lives matter: claiming a space for evidence-based outrage in obstetrics and gynecology. Am J Public Health. 2016;106:1771-2.

71. Creanga A, Berg C, Ko J, Farr SL, Tong VT, Bruce FC, et al. Maternal mortality and morbidity in the United States: Where are we now? J Womens Health. 2014:23:3-9.

72. Creanga A, Berg C, Syverson C, Seed K, Bruce C, Callaghan W. Pregnancyrelated mortality in the United States, 2006-2010. Obstet Gynecol. 2015; 125(1):5-12.

73. Creanga AA, Bateman BT, Kuklina EV, Callaghan WM. Racial and ethnic disparities in severe maternal morbidity: a multisite analysis, 2008-2010. Am J Obstet Gynecol. 2014;210:435.e1-8.

74. Handler A, Johnson K. A call to revisit the prenatal period as a focus for action within the reproductive and perinatal care continuum. Matern Child Health J. 2016:20:2217-27.

\section{Submit your next manuscript to BioMed Central and we will help you at every step:}

- We accept pre-submission inquiries

- Our selector tool helps you to find the most relevant journal

- We provide round the clock customer support

- Convenient online submission

- Thorough peer review

- Inclusion in PubMed and all major indexing services

- Maximum visibility for your research

Submit your manuscript at www.biomedcentral.com/submit 